\title{
Stilianos E. Kountakis, Joseph Jacobs, Jan Gosepath (eds): Revision sinus surgery
}

\author{
Springer, 2008. ISBN 978-3-540-78930-7
}

\author{
Jean Michel Klossek
}

Received: 4 January 2009/Accepted: 6 January 2009/Published online: 24 January 2009

(C) Springer-Verlag 2009

This book is original because it focuses on revision surgery. The large number and the quality of contributors give quality to this publication. Through the different chapters, the various problems of revision cases are well described, from the analysis of the failure to the surgical technique required. The preoperative assessments are well documented including radiology, preoperative medical treatment, etc.

From resident to expert, everybody will find a documentation adapted to all situations. This large overview is a valuable asset not only before taking charge of patients for revision surgery, but also to analyze one's own results and to improve one's experience. Almost all procedures are presented in this publication. The experienced contributors describe their experience, confirming the difficulty of this surgery from its indication to realization. Postoperative managements are also thoroughly described. New technologies are presented and discussed. The quality of the bibliography of each chapter is an additional advantage to this book. The DVD accompanying the publication is a good opportunity to complete the reading and to view the different techniques described.

In summation, this book will probably become a cornerstone of the library of all present and future endoscopic surgeons. 